\title{
Classification of Weathered Kerosene and Diesel Fuel using Passive Headspace Concentration with Activated Charcoal Strip and Statistical Analysis Technique
}

\section{Latoya Wright $^{1-4 *}$ and Lisha Reid ${ }^{1}$}

${ }^{1}$ Department of Chemistry, Institute of Forensic Science and Legal Medicine, Jamaica

${ }^{2}$ International Association of Law Enforcement Intelligence Analysts (IALEIA), USA

${ }^{3}$ Caribbean Association of Forensic Sciences (CAFS), Jamaica

${ }^{4}$ The International Association of Forensic Toxicologists (TIAFT), USA

\begin{abstract}
Ignitable liquids are present in trace amounts in samples collected from arson scenes therefore their chemical composition often differs from their original composition. This is due to partial evaporation, burning and contamination by pyrolysis products at the scenes.

The research was done using two techniques, passive headspace concentration with activated charcoal strip and statistical Analysis, to classify weathered kerosene and diesel fuel. The passive headspace used GC-FID chromatogram pattern to visually identify both weathered ignitable liquids while statistical analysis used cluster formation to group them based on unique characteristics of their hydrocarbons and materials used in the samples.

Four case studies were done which consisted of forty-two experiments carried out on twenty-six weathered and unweathered samples that were analyzed under various conditions which included various time of burning, weathering and oven temperature. The Petroleum based ignitable liquids, kerosene and diesel, were used on different types of materials for analysis under various atmospheric conditions.

The result showed visual distinction between weathered kerosene and diesel fuel at the initial stage of weathering but it was more difficult to distinguish as samples became weathered over time. Hence, this is one of the reasons why the chromatogram alone cannot be used to visually distinguish between these weathered samples. Therefore, the combination of the chromatographic pattern and statistical method were applied in this research.

It was possible to distinguish between the weathered kerosene and diesel fuel using statistical analysis based on n-alkane data derived from Gas Chromatography- Flame Ionization Detector (GC-FID) method.
\end{abstract}

Keywords: Gas chromatography-Flame ionization detector; Weathered kerosene and diesel fuel; Statistical analysis; Principal component analysis; Component profile; Hydrocarbons; Pristane and phytane

\section{Introduction}

Ignitable liquid is a simple flammable or combustible liquid and any of which that can be used as an accelerant. An accelerant is anything used to intentionally start or spread a fire and is often an ignitable liquid; however, an ignitable liquid, even when identified in fire debris is not necessarily an accelerant $[1,2]$.

Ignitable liquids can be broadly categorized as petroleum or nonpetroleum. Petroleum-based ignitable liquids are refined from crude oil. $\mathrm{N}$-alkanes are often used as retention time or elution order markers for ignitable liquid data interpretation. Petroleum products /ignitable liquids contain alkane and or aromatic hydrocarbon compounds [2].

Petroleum products are usually grouped into three categories; light, middle and heavy distillates. Middle distillates include kerosene has overlapping carbon number distribution, C9-C15 for kerosene shown in Figure 1 and C12-C22 for diesel (heavy) in Figure 2. Most of the physico-chemical properties are dependent on the composition of hydrocarbon present in the fuel [3].

Heavy petroleum distillates contain the important natural markers, pristane and phytane (isoprenoid compounds) which elute shortly after $\mathrm{n}-\mathrm{C} 17$ and n-C18 respectively. Figure 2 shows the presence of peak doublets at $\mathrm{C} 17$ and $\mathrm{C} 18$ of a heavy distillate, fresh or unweathered diesel [4].
The major components present are the twelve dominant alkanes that peak at regular intervals over the chromatogram ranging from $\mathrm{n}-\mathrm{C} 10$ to $\mathrm{n}-\mathrm{C} 21$ which are typical of diesel [5] also shown in Figure 2. In field or weathered diesel, the $\mathrm{n}-\mathrm{C} 17$, which elute before pristane, is absent or significantly weathered while the $\mathrm{n}-\mathrm{C} 18$, which elute before phytane, is relatively small due to biodegradation. Reason being is that ratio of $\mathrm{n}-\mathrm{C} 17$ is correlated to age of diesel spill [5].

Most ignitable liquids contain hundreds of compounds in relatively broad boiling ranges therefore the effect of environmental stressors (exposure, heat) can result in notable changes in the chromatographic pattern. More volatile compounds evaporate at a higher rate than less volatile compounds. This evaporation also called "weathering", results in a shift of the chromatographic pattern towards higher boiling compounds. The impact of the weathering on ignitable liquid

*Corresponding author: Latoya Wright, Forensic Officer, Department of Chemistry, Institute of Forensic Science and Legal Medicine, Jamaica, Tel: 8769064908; E-mail: law_tlc@yahoo.com

Received December 07, 2016; Accepted December 12, 2017; Published December 18, 2017

Citation: Wright L, Reid L (2017) Classification of Weathered Kerosene and Diesel Fuel using Passive Headspace Concentration with Activated Charcoal Strip and Statistical Analysis Technique. J Forensic Res 8: 403. doi: 10.4172/21577145.1000403

Copyright: ( 2017 Wright L, et al. This is an open-access article distributed under the terms of the Creative Commons Attribution License, which permits unrestricted use, distribution, and reproduction in any medium, provided the original author and source are credited. 
Citation: Wright L, Reid I (2017) Classification of Weathered Kerosene and Diesel Fuel using Passive Headspace Concentration with Activated Charcoal Strip and Statistical Analysis Technique. J Forensic Res 8: 403. doi: 10.4172/2157-7145.1000403

composition and thus data presentation is dependent on the range of the product and the amount of evaporation [2]. The "hump" of hydrocarbons is a common feature of gas chromatograms of crude oil and certain refined products and is especially pronounced for weathered and biodegraded oils [6].

The small quantification difference in the chemical composition of weathered kerosene and diesel fuel samples caused problems in differentiation due to their physiochemical properties [1], Hence the GC-FID chromatographic pattern alone cannot be used to distinguish between them. Therefore, the combination of the chromatogram pattern and statistical analysis techniques were used to accurately classify weathered kerosene and diesel fuel.

\section{Instruments and Experimental Method}

Passive Headspace Method used ASTME 1412-00 STANDARD [7].

\section{GC-FID analysis}

ASTME1412-00 Standard was used and nitrogen used as the carrier gas on the GC-FID.

All analyses were performed using an Agilent 7890A gas chromatography (Agilent Technologies, Santa Clara. CA) and equipped with an Agilent HP-5 capillary column $(30 \mathrm{~m} \times 320 \mu \mathrm{m} \times 0.25 \mu \mathrm{m})$. The temperature was $250^{\circ} \mathrm{C}$ and $1 \mu \mathrm{L}$ of the sample was injected in split less mode using an Agilent 7683B series automated liquid sampler. The GC temperature program had an initial temperature of $50^{\circ} \mathrm{C}$ for 5 minutes, was ramped to $230^{\circ} \mathrm{C}$ at $100^{\circ} \mathrm{C} /$ minutes, and held at $230^{\circ} \mathrm{C}$ for 8 minutes.

\section{Experiment}

Four case studies were done which included forty-two experiments carried out on twenty-six weathered and unweathered samples. Both ignitable liquids (kerosene and diesel) were extracted by using adsorption and desorption with activated carbon strips, and the resulting extract (eluent/elute) was analyzed by GC-FID to identify the components present. Experiments were done at various times of burning, weathering and external atmosphere exposure between 10-15 minutes. Samples included vegetation, woodchips, pebbles, sand, soil, concrete and pieces of clothing such as denim material, polyester and cotton. Unweathered/Standard kerosene and diesel were also analyzed (Figures 1 and 2).

\section{Case study 1}

On April 17, $20135 \mathrm{ml}$ of diesel fuel was spiked onto a $5 \times 5$ piece of denim cloth and $5 \mathrm{ml}$ kerosene was spiked onto another $5 \times 5 \mathrm{~cm}$ piece of denim cloth. $5 \mathrm{ml}$ of diesel was spiked on a $5 \times 5 \mathrm{~cm}$ piece of denim cloth mixed with vegetation, woodchips, soil and pebbles and $5 \mathrm{ml}$ kerosene was spiked onto another $5 \times 5 \mathrm{~cm}$ piece of denim cloth. Each mixed sample except the denim cloth was ignited for 2 minutes, forming burnt debris, and then the fire was extinguished with water. All four were placed in the adsorption oven and the temperature was set at $60^{\circ} \mathrm{C}$ for the first set of eight experiments and at $80^{\circ} \mathrm{C}$ for samples that were left overnight exposed to the external atmospheric environment for 16 hours. They were all packaged on April 18, 19 and 22, 2013 and May 15 and 16, 2013 respectively. The last four experiments; however, were all set at a constant oven time of 16 hours. GC-FID analysis was done on all 4 samples on April 19, 2013, April 23, 2013 and May 22, 2013 respectively and analyzed (Tables 1 and 2).

\section{Case study 2}

On April 25, $201310 \mathrm{ml}$ of diesel fuel was spiked onto a $8 \times 8 \mathrm{~cm}$ piece of denim cloth and $10 \mathrm{ml}$ kerosene was spiked onto another $8 \times$ $8 \mathrm{~cm}$ piece of denim cloth. $10 \mathrm{ml}$ of diesel were spiked onto an $8 \times 8$ $\mathrm{cm}$ piece of denim cloth mixed with vegetation, woodchips, soil and pebbles and $10 \mathrm{ml}$ kerosene was spiked on another $8 \times 8 \mathrm{~cm}$ piece of denim cloth mixed with the same material as the latter. Each mixed sample was ignited for 4 minutes, forming burnt debris, and then the fire was extinguished with water. All four samples were left exposed for a day and overnight to the external atmospheric environment for 24 hours. They were all packaged on April 26, 2013. The adsorption oven temperature was set at constant temperature of $80^{\circ} \mathrm{C}$ for all 12 experiments but oven time period varied from 24 hours, 26 hours and 16 hours respectively. GC-FID analysis was done on all four samples on May 5, 2013, May 13, 2013 and May 22 and 24, 2013 respectively and analyzed (Tables 1 and 2).

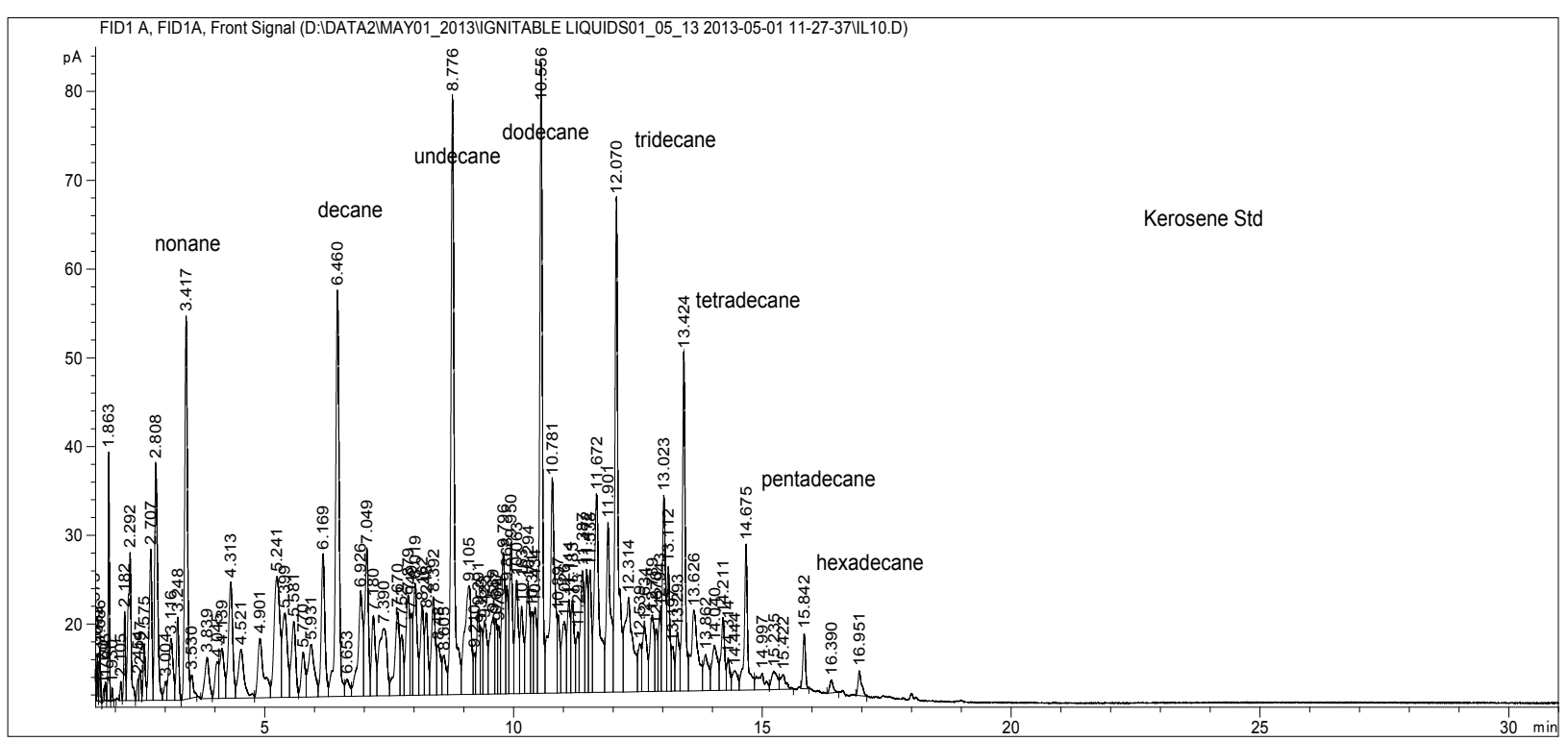

Figure 1: Kerosene standard GC-FID chromatogram profile illustrating the major n-alkanes, C9-Nonane, C1O-Decane, C11-Undecane, C12-Dodecane C13Tridecane, C14-Tetradecane, C15-Pentadecane and C6-hexadecane. 
Citation: Wright L, Reid I (2017) Classification of Weathered Kerosene and Diesel Fuel using Passive Headspace Concentration with Activated Charcoal Strip and Statistical Analysis Technique. J Forensic Res 8: 403. doi: 10.4172/2157-7145.1000403

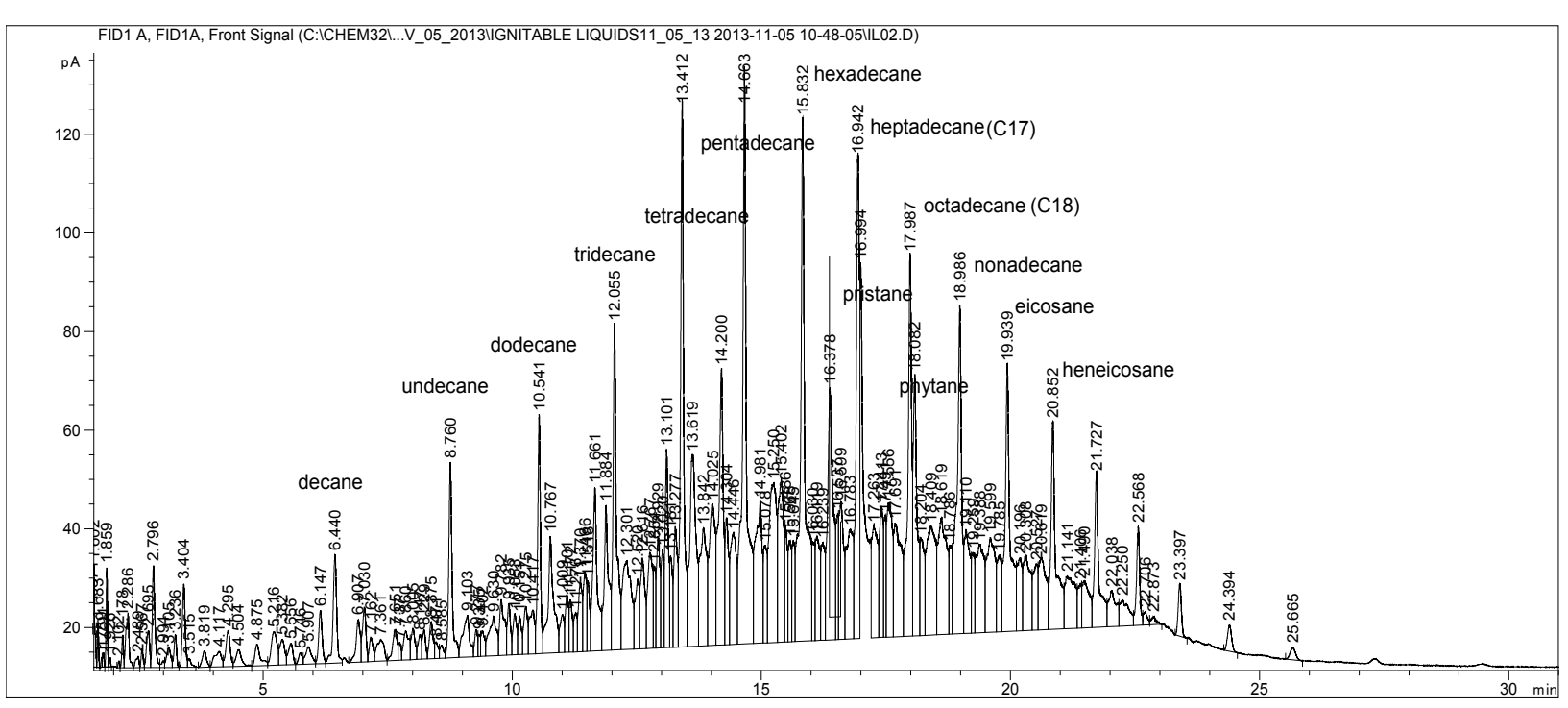

Figure 2: Diesel standard GC-FID chromatogram profile illustrating the 12-major n-alkanes, C9-Nonane, C1O-Decane, C11-Undecane, C12-Dodecane C13Tridecane, C14-Tetradecane, C15-Pentadecane, C16-hexadecane, C17-heptadecane, C18- octadecane, C19-nonadecane, C20-eicosane and C21-heneicosane.

\begin{tabular}{|c|c|c|c|c|c|}
\hline Case Studies & Weathered Time/hours & Experiment \# & Samples & $\begin{array}{l}\text { Adsorption Oven Temp and Time/ } \\
\text { hours }\end{array}$ & FID Analysis \\
\hline \multirow{3}{*}{1} & \multirow{3}{*}{ April 17-18 201316 hrs } & $1-4$ & $\begin{array}{l}\mathrm{A} 1-\mathrm{A} 2 \\
\mathrm{~B} 1-\mathrm{B} 2\end{array}$ & $\begin{array}{l}60^{\circ} \mathrm{C} \\
\text { April 18-19 } 2013 / 16 \mathrm{hrs}\end{array}$ & April 19, 2013 \\
\hline & & $5-8$ & $\begin{array}{l}\text { A1-A2 } \\
\text { B1-B2 }\end{array}$ & $\begin{array}{l}60^{\circ} \mathrm{C} \\
\text { April 22-23, 2013/16 hrs }\end{array}$ & April 23, 2013 \\
\hline & & $9-12$ & $\begin{array}{l}\mathrm{A} 1-\mathrm{A} 2 \\
\mathrm{~B} 1-\mathrm{B} 2\end{array}$ & $\begin{array}{l}80^{\circ} \mathrm{C} \\
\text { May } 15-16,2013 / 16 \mathrm{hrs}\end{array}$ & May 22, 2013 \\
\hline \multirow{3}{*}{2} & \multirow{3}{*}{ April 25-26, $201324 \mathrm{hrs}$} & $13-16$ & $\begin{array}{l}\mathrm{A} 1-\mathrm{A} 2 \\
\mathrm{~B} 1-\mathrm{B} 2\end{array}$ & $\begin{array}{l}80^{\circ} \mathrm{C} \\
\text { April } 30 \text { - May 5,2013/24hrs }\end{array}$ & May 5, 2013 \\
\hline & & $17-20$ & $\begin{array}{l}\mathrm{A} 1-\mathrm{A} 2 \\
\mathrm{~B} 1-\mathrm{B} 2\end{array}$ & $\begin{array}{l}80^{\circ} \mathrm{C} \\
\text { May 6-7,2013/26 hrs }\end{array}$ & May 13, 2013 \\
\hline & & $21-24$ & $\begin{array}{l}\mathrm{A} 1-\mathrm{A} 2 \\
\mathrm{~B} 1-\mathrm{B} 2\end{array}$ & $\begin{array}{l}80^{\circ} \mathrm{C} \\
\text { May } 15-16,2013 / 16 \mathrm{hrs}\end{array}$ & $\begin{array}{l}\text { May 22, } 2013 \text { and } \\
\text { May } 24,2013\end{array}$ \\
\hline 3 & October $16-17,2013,<15$ minutes & $1-12$ & $\begin{array}{l}\text { A3-A8 } \\
\text { B3-B8 }\end{array}$ & $\begin{array}{l}70^{\circ} \mathrm{C} \\
\text { October } 17-18,2013 / 16 \mathrm{hrs}\end{array}$ & October 28, 2013 \\
\hline 4 & October 22- 23, 201324 hrs & $1-6$ & $\begin{array}{l}\text { A9-11 } \\
\text { B9-11 }\end{array}$ & $\begin{array}{l}70^{\circ} \mathrm{C} \\
\text { October 22-23, 2013/16 hrs }\end{array}$ & October 28-29, 2013 \\
\hline
\end{tabular}

Table 1: Illustrating the Case Studies.

\section{Case study 3}

On October 16, $20135 \mathrm{ml}$ of diesel fuel was spiked on $10 \times 10$ pieces of clothing which included cotton, polyester and denim cloth. Another $5 \mathrm{ml}$ of diesel was also spiked on samples of sand and soil, and concrete. The same was done with kerosene. All six samples were packaged immediately after spiking. Another set of samples, as described above, were spiked with diesel fuel, ignited for 2 minutes and then extinguished with water. The same was done with kerosene. All six burnt samples were immediately packaged after cooling. The adsorption oven temperature was set at $70^{\circ} \mathrm{C}$ for all 12 experiments for approximately 16 hours. GC-FID analysis was done on all twelve samples on October 28, 2013 and analysed (Tables 1 and 2).

\section{Case study 4}

On October 22, $20135 \mathrm{ml}$ of diesel fuel was spiked on $10 \times 10$ pieces of clothing, which included cotton, polyester and denim. Another $5 \mathrm{ml}$ of diesel fuel was also spiked on samples of sand and soil, concrete and clothing mixed with vegetation, woodchip and cardboard. The same was done with kerosene. Each sample was ignited for 2 minutes and then extinguished with water. All six samples were left exposed overnight to the external atmospheric environment for 24 hours. They were all packaged on October 23, 2013. The adsorption oven temperature was set at a constant temperature of $70^{\circ} \mathrm{C}$ for all 6 experiments for approximately 16 hours. GC-FID analysis was done on all six samples on October 28 and 29, 2013 (Tables 1 and 2).

\section{Discussion and Result}

\section{Some factors that affect weathering kerosene and diesel fuel}

There are several factors that affect weathering on kerosene and diesel fuel. Some of these include air, water and biodegradation.

- Air: - evaporation, occurring when petroleum is in contact with air, causing constituents to volatilize.

- Water: - dissolution, occurring when petroleum is in contact with water, causing constituents to dissolve.

- Biodegradation: - the digestion of petroleum constituents by microbes which degrades hydrocarbons in soil. 
Citation: Wright L, Reid I (2017) Classification of Weathered Kerosene and Diesel Fuel using Passive Headspace Concentration with Activated Charcoal Strip and Statistical Analysis Technique. J Forensic Res 8: 403. doi: 10.4172/2157-7145.1000403

Four samples (spiked denim cloth material) left to weather by evaporation were only affected by air while the other four samples (burnt debris) were affected by all three factors of air, water and biodegradation [8].

\section{Results interpretation}

Chromatographic analysis: The Chromatogram pattern of weathered an unweathered kerosene and diesel were observed and visually compared. These were based on retention time of n-alkanes, reduction in the number of $\mathrm{n}$-alkanes present and shift in baseline of the component profile.

In case study 1 it was observed that the GC-FID chromatogram pattern, for the burnt debris and cloth weathered kerosene and diesel samples, at higher oven temperature of $80^{\circ} \mathrm{C}$, showed lighter molecules of $\mathrm{n}$-alkanes and these diminishing in small amount. Also the peaks were more defined when compared to lower oven temperature at $60^{\circ} \mathrm{C}$. See Figure $3 \mathrm{a}$ and $3 \mathrm{~b}$ at $60^{\circ} \mathrm{C}$ and Figure $3 \mathrm{c}$ at $80^{\circ} \mathrm{C}$. For the unburnt spiked denim cloth for diesel similarities were observed to

\begin{tabular}{|c|c|}
\hline \multicolumn{2}{|c|}{ Case Study 1 (burnt weathered samples-16 hours exposure) } \\
\hline $\begin{array}{l}\text { Diesel } \\
\text { A1-diesel burnt debris } \\
\text { A2-diesel burnt cloth }\end{array}$ & $\begin{array}{l}\text { Kerosene } \\
\text { B1-kerosene burnt debris } \\
\text { B2-kerosene burnt cloth }\end{array}$ \\
\hline \multicolumn{2}{|c|}{ Case Study 2(burnt weathered samples-24 hours exposure) } \\
\hline $\begin{array}{l}\text { Diesel } \\
\text { A1-diesel burnt debris } \\
\text { A2-diesel burnt cloth) } \\
{ }^{1} \mathrm{~A} 2\end{array}$ & $\begin{array}{l}\text { Kerosene } \\
\text { B1-kerosene burnt debris } \\
\text { B2-kerosene burnt cloth } \\
{ }^{1} \text { B2 }\end{array}$ \\
\hline \multicolumn{2}{|c|}{ Case Study 3 (unweathered STD and burnt samples-less than 15 minutes exposure) } \\
\hline $\begin{array}{l}\text { Diesel } \\
\text { A3-cloth (polyester, cotton) STD } \\
\text { A4-sand and soil STD } \\
\text { A5-concrete STD } \\
\text { A6-burnt sand and soil } \\
\text { A7-burnt cloth } \\
\text { A8-burnt concrete }\end{array}$ & $\begin{array}{l}\text { Kerosene } \\
\text { B3- cloth (polyester, cotton) STD } \\
\text { B4- sand and soil STD } \\
\text { B5-concrete STD } \\
\text { B6-burnt sand and soil } \\
\text { B7-burnt cloth } \\
\text { B8-burnt concrete }\end{array}$ \\
\hline \multicolumn{2}{|c|}{ Case Study 4 (burnt weathered samples-24 hours exposure) } \\
\hline $\begin{array}{l}\text { Diesel } \\
\text { A9-weathered burnt clothing } \\
\text { A10-weathered burnt sand andsoil } \\
\text { A11-weathered burnt concrete }\end{array}$ & $\begin{array}{l}\text { Kerosene } \\
\text { B9-weathered burnt clothing } \\
\text { B10-weathered burnt sand and soil } \\
\text { B11-weathered burnt concrete }\end{array}$ \\
\hline
\end{tabular}

*Note: Cloth/clothing (polyester, cotton/denim), STD: Standard; petroleum in its pure form

${ }^{1}$ the adsorption oven temperature was set at $60^{\circ} \mathrm{C}$ for the first set of samples and repeated at and $80^{\circ} \mathrm{C}$

Table 2: Illustrating legend for the experiment done in case studies.

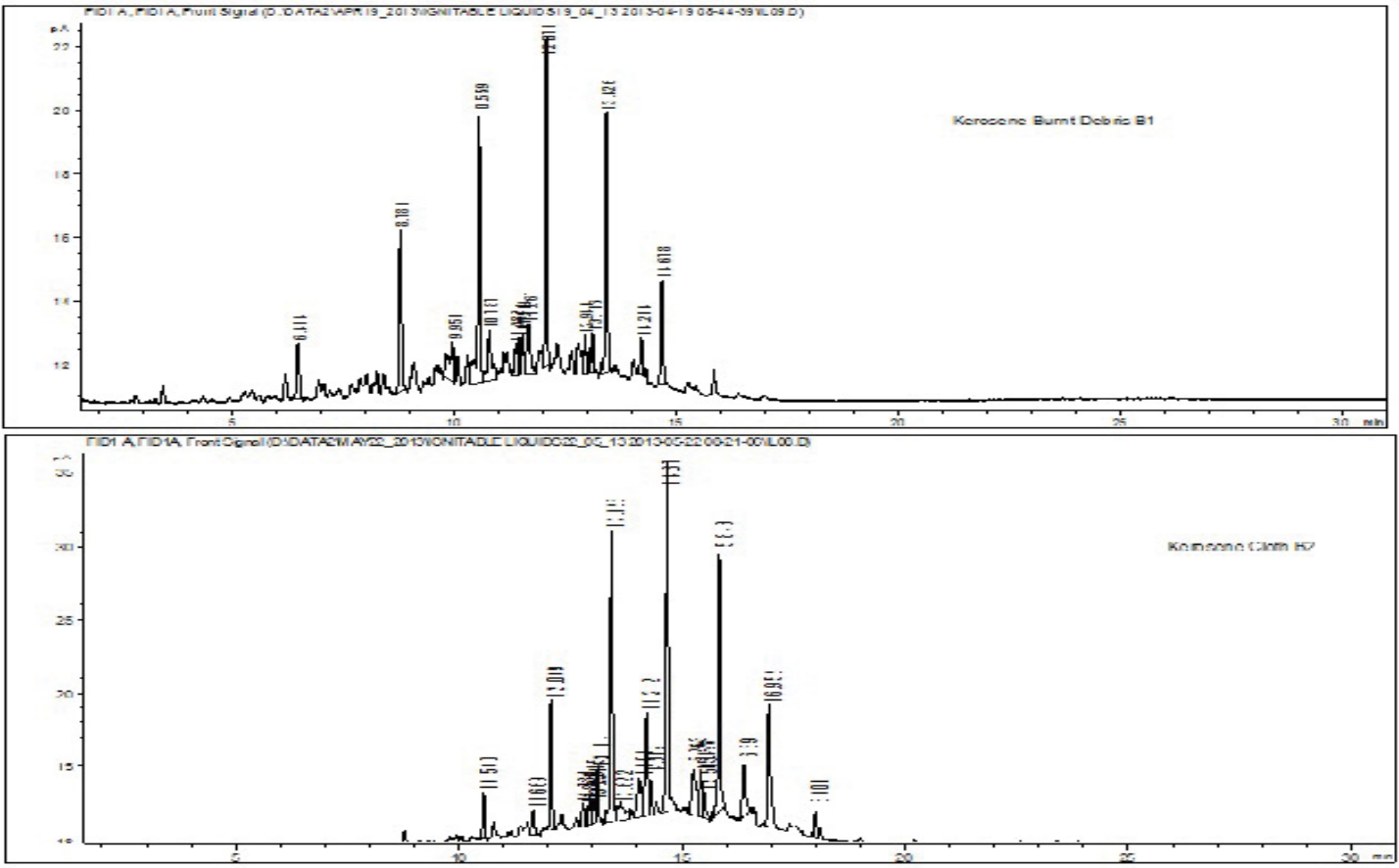

Figure 3a and 3b: 3a: Illustrating chromatogram pattern for weathered and unweathered kerosene burnt debris and cloth samples, respectively, at $60^{\circ} \mathrm{C}, 3 \mathbf{b}$ : Illustrating chromatogram pattern for weathered and unweathered burnt debris and cloth diesel samples, respectively, at $60^{\circ} \mathrm{C}$. 
Citation: Wright L, Reid I (2017) Classification of Weathered Kerosene and Diesel Fuel using Passive Headspace Concentration with Activated Charcoal Strip and Statistical Analysis Technique. J Forensic Res 8: 403. doi: 10.4172/2157-7145.1000403
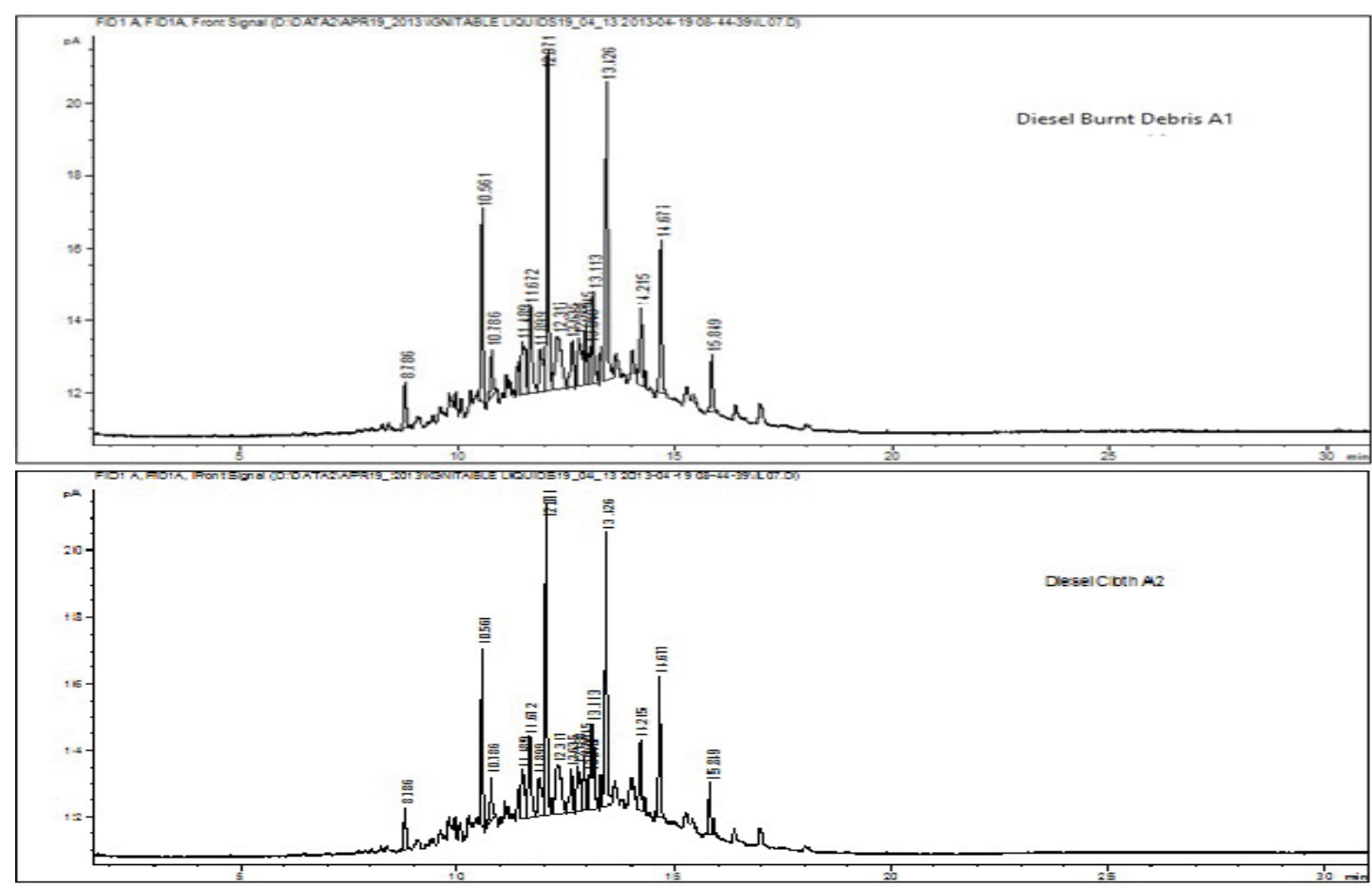

Figure 3c: Illustrating chromatogram pattern for weathered diesel and kerosene samples at $80^{\circ} \mathrm{C}$

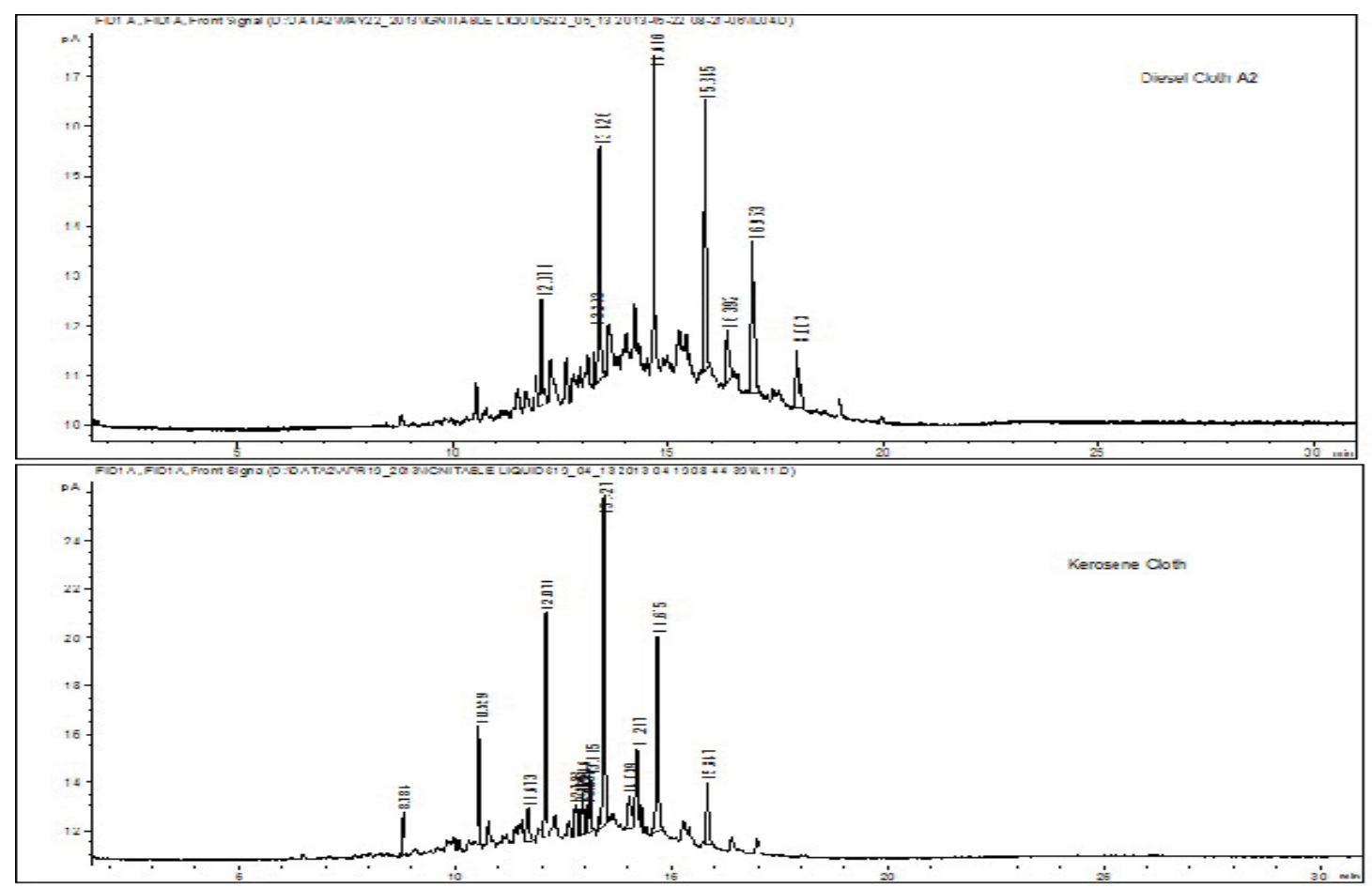

Figure 4: Illustrating chromatogram pattern for burnt and unburnt diesel sample both showing the prominent feature of an exaggerated "hump" at the baseline.

the burnt debris at both oven temperature of $60^{\circ} \mathrm{C}$ and $80^{\circ} \mathrm{C}$, However, the diminishing n-alkanes created a more pronounce component profile shift in the baseline forming an exaggerated "hump" (envelope) (Figure 4).
In case study 2 at a constant adsorption oven temperature of $80^{\circ} \mathrm{C}$ and different oven times for both weathered kerosene and diesel fuel samples, more volatile $\mathrm{n}$-alkanes were diminished but the component 
Citation: Wright L, Reid I (2017) Classification of Weathered Kerosene and Diesel Fuel using Passive Headspace Concentration with Activated Charcoal Strip and Statistical Analysis Technique. J Forensic Res 8: 403. doi: 10.4172/2157-7145.1000403

profile of the GC-FID chromatogram pattern had more defined peaks (Figure 3c).

It was also observed that at the initial stage of the weathered burnt debris the GC-FID chromatogram pattern could be easily identified between the weathered kerosene and diesel fuel (Figure 5). It was also observed that, for the spiked denim cloth, the more prominent visual feature of the differences between the weathered kerosene and diesel fuel was the exaggerated hump as seen in the weathered diesel chromatogram profile which was also observed in diesel burnt debris (Figure 5). This is the effect of "weathering" process as the component profile shifts to the higher boiling range and loses the regularly spaced n-alkane peaks [9]. However, it was also observed that as all the samples (from initial stage of case study 1 to the final stage of case study 2) became more weathered they showed similar chromatogram pattern (Figure 6) when the weathered diesel cloth was compared to the weathered kerosene cloth.

In case study 3 samples were unweathered however, GC-FID chromatogram pattern for all samples showed diminishing of the lighter $\mathrm{n}$-alkane peaks to some extent but not on a greater scale compared to case study 1 and 2 . Figures $7 \mathrm{a}$ and $7 \mathrm{~b}$ showing unweathered diesel and kerosene samples cloth and debris respectively.

In case study 4 the weathered burnt debris GC-FID chromatogram pattern showed a similar pattern to those in case study 1 and 2 but the weathered burnt sand and soil and concrete showed similar chromatogram pattern to those of unweathered in case study 3 (Figure $7 \mathrm{a}, 7 \mathrm{~b}$ and Figure $8 \mathrm{a}, 8 \mathrm{~b})$.

The use of headspace technique as a sample preparation step can make the differentiation between kerosene and diesel fuel difficult due to insufficient adsorption of high-boiling compounds i.e. adsorption oven temperature too low. However, the use of higher adsorption temperature can resolve this problem to some extent but if temperature is too high it will result in adverse effect on the hydrocarbons. The higher the adsorption temperature the more defined the chromatogram peaks are but more diminishing peaks [1] are seen as illustrated in Figure $3 \mathrm{a}-3 \mathrm{c}$. Therefore, an oven temperature of $70^{\circ} \mathrm{C}$ was observed to be more suitable.

\section{Statistical analysis}

The statistical analysis information used was based on peak area and retention time obtained from the GC-FID chromatogram data which were analyzed using Tanagra software.

The data sets from the GC-FID chromatogram data were examined and preprocessed i.e. dominant $\mathrm{n}$-alkanes peak areas were manually selected as variables. The peak areas and retention time of these dominant n-alkanes were collected using excel spreadsheet and the data in excel was executed in Tanagra. The data was then analyzed using Principal Component Analysis (PCA) and supervised learning (error analysis)

Tanagra is an open source data mining software designed primarily for academics and research purposes. It supports a large set of functionalities which include clustering, factorial analysis which uses the principal component analysis, and other analysis techniques.

Factorial analysis identifies the underlying factors which explain the relationships between correlated variables. The correlation of variables is the measure of association between variables i.e change in one variable is reliable on the change in another variable. Principal component analysis (PCA) simply reduces the number of variables by finding the linear combination of variables that explains the variances

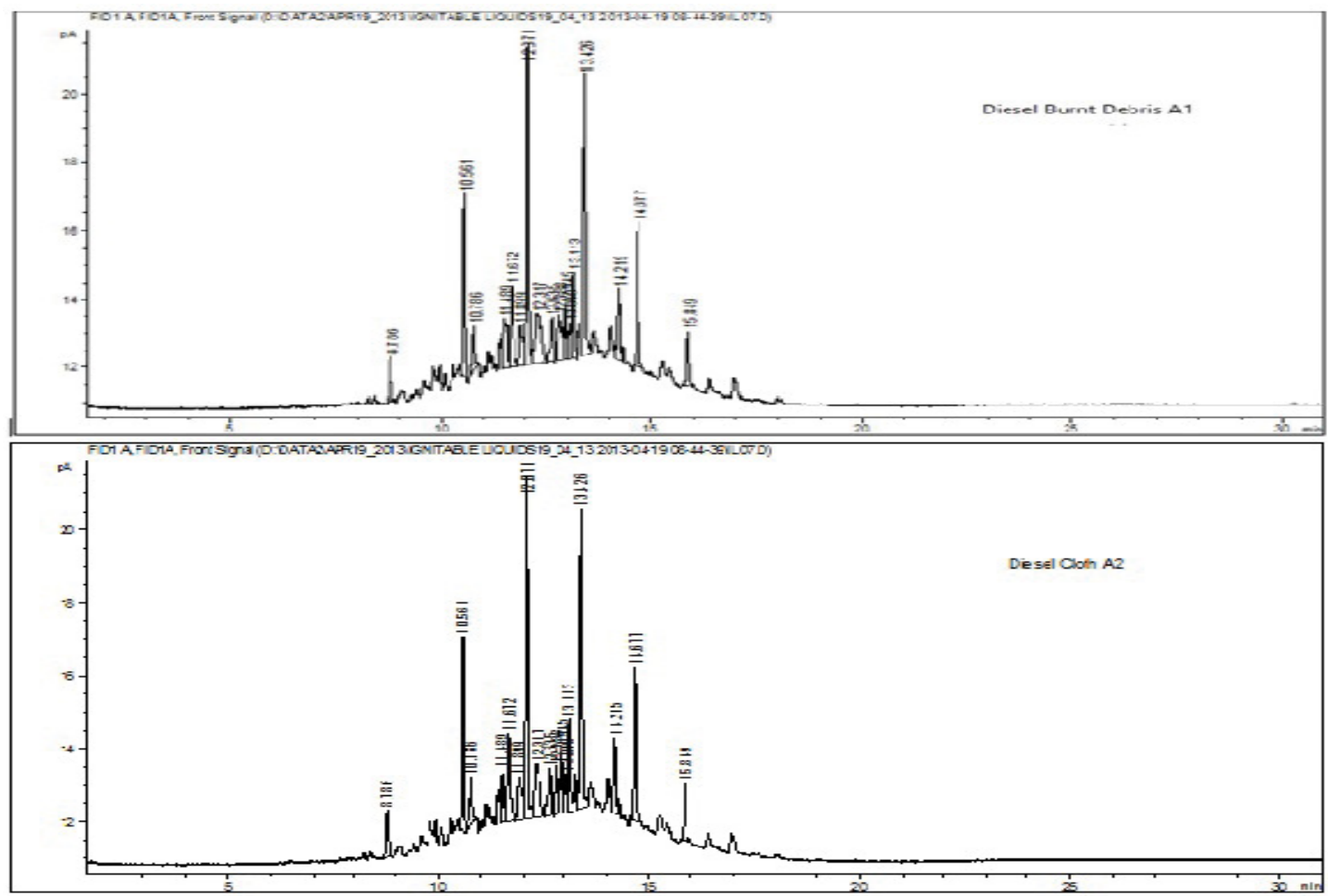

Figure 5: Illustrating chromatogram pattern for the initial stage of the weathered burnt debris of kerosene and diesel (exaggerated "hump" as the most prominent feature at baseline). 
Citation: Wright L, Reid I (2017) Classification of Weathered Kerosene and Diesel Fuel using Passive Headspace Concentration with Activated Charcoal Strip and Statistical Analysis Technique. J Forensic Res 8: 403. doi: 10.4172/2157-7145.1000403
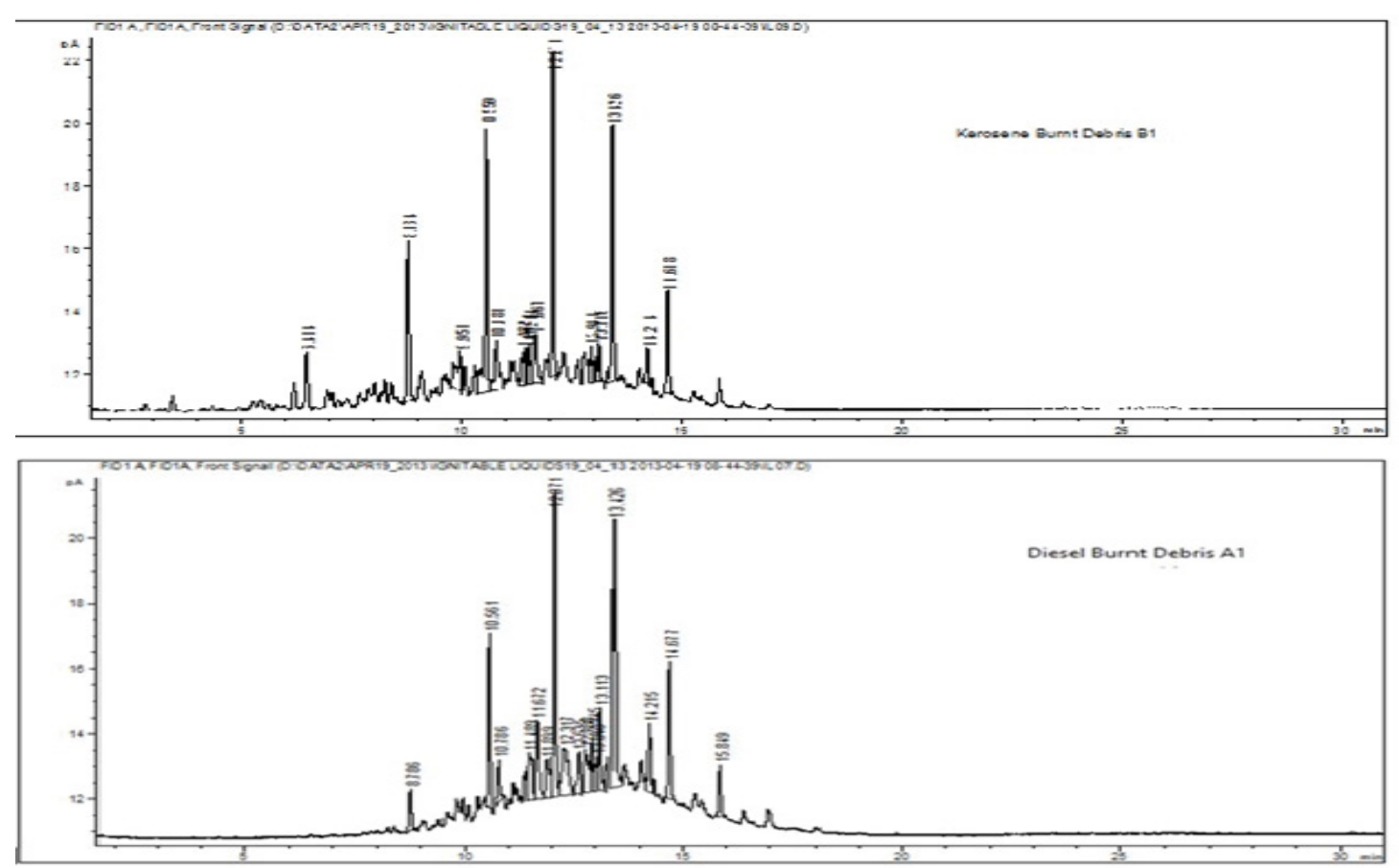

Figure 6: Weathered diesel cloth compare to weathered kerosene cloth.
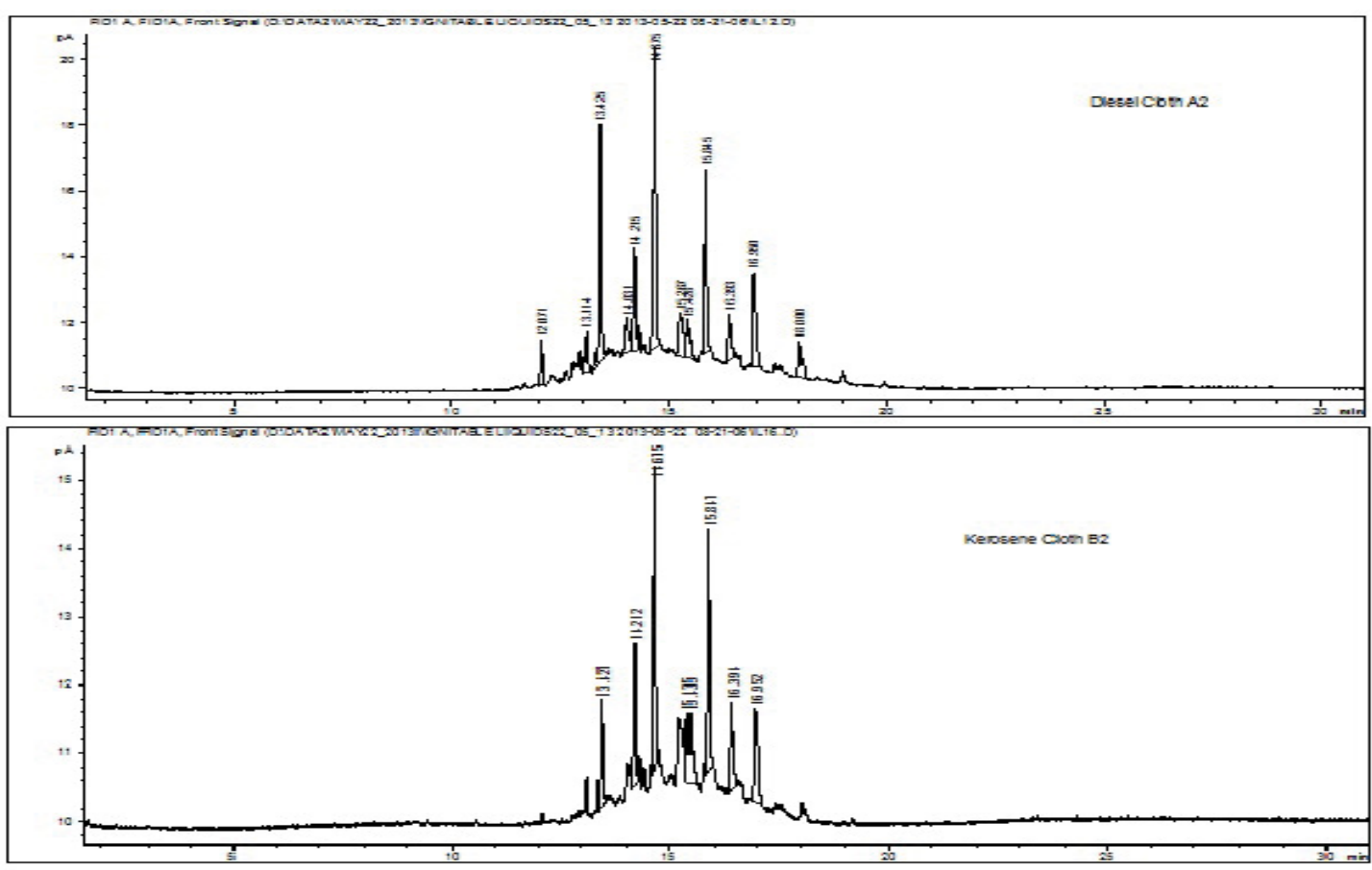

Figure 7a: Illustrating chromatogram pattern for unweathered cloth and debris diesel samples.

of the original variables. PCA is one of the most common pattern recognition techniques reported in the forensic science literature. It's a means of identifying patterns or clusters in data which highlights their similarities and differences. PCA was performed on the data set and a score plot was obtained producing the first two principal components (PCs). PCs are most commonly used to display the cluster outcomes of a given data set where samples having similar scores are positioned closely together. The score plot of the first 2 PCs (axis 1 and 2) is most commonly used to display the clusters outcomes of a given data set where samples having similar scores are positioned closely together. The plot also provides an important means of visualizing and summarizing the original data set and often reveals patterns that were previously elusive [10]. 
Citation: Wright L, Reid I (2017) Classification of Weathered Kerosene and Diesel Fuel using Passive Headspace Concentration with Activated Charcoal Strip and Statistical Analysis Technique. J Forensic Res 8: 403. doi: 10.4172/2157-7145.1000403
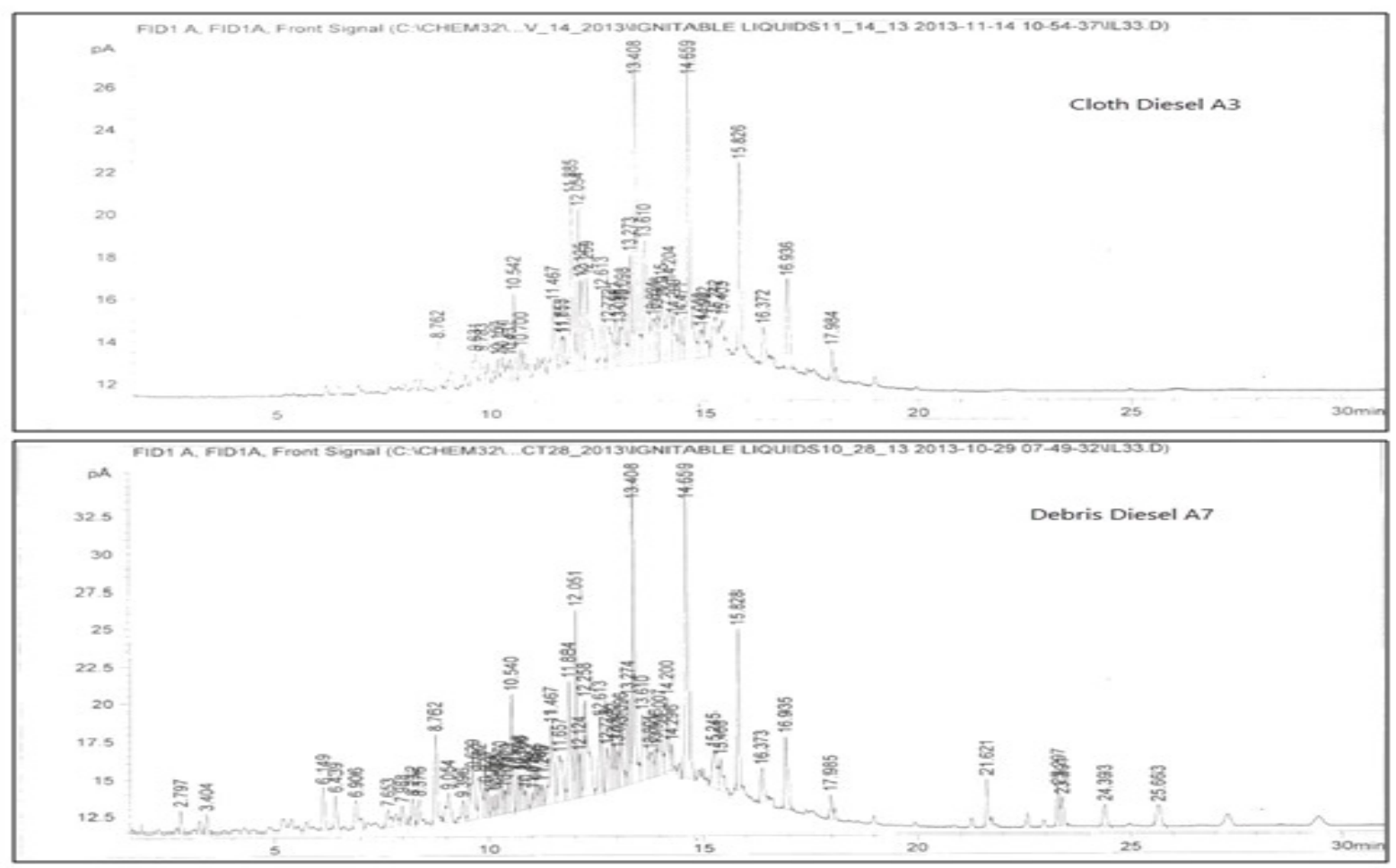

Figure 7b: Illustrating chromatogram pattern for unweathered kerosene cloth and debris samples.
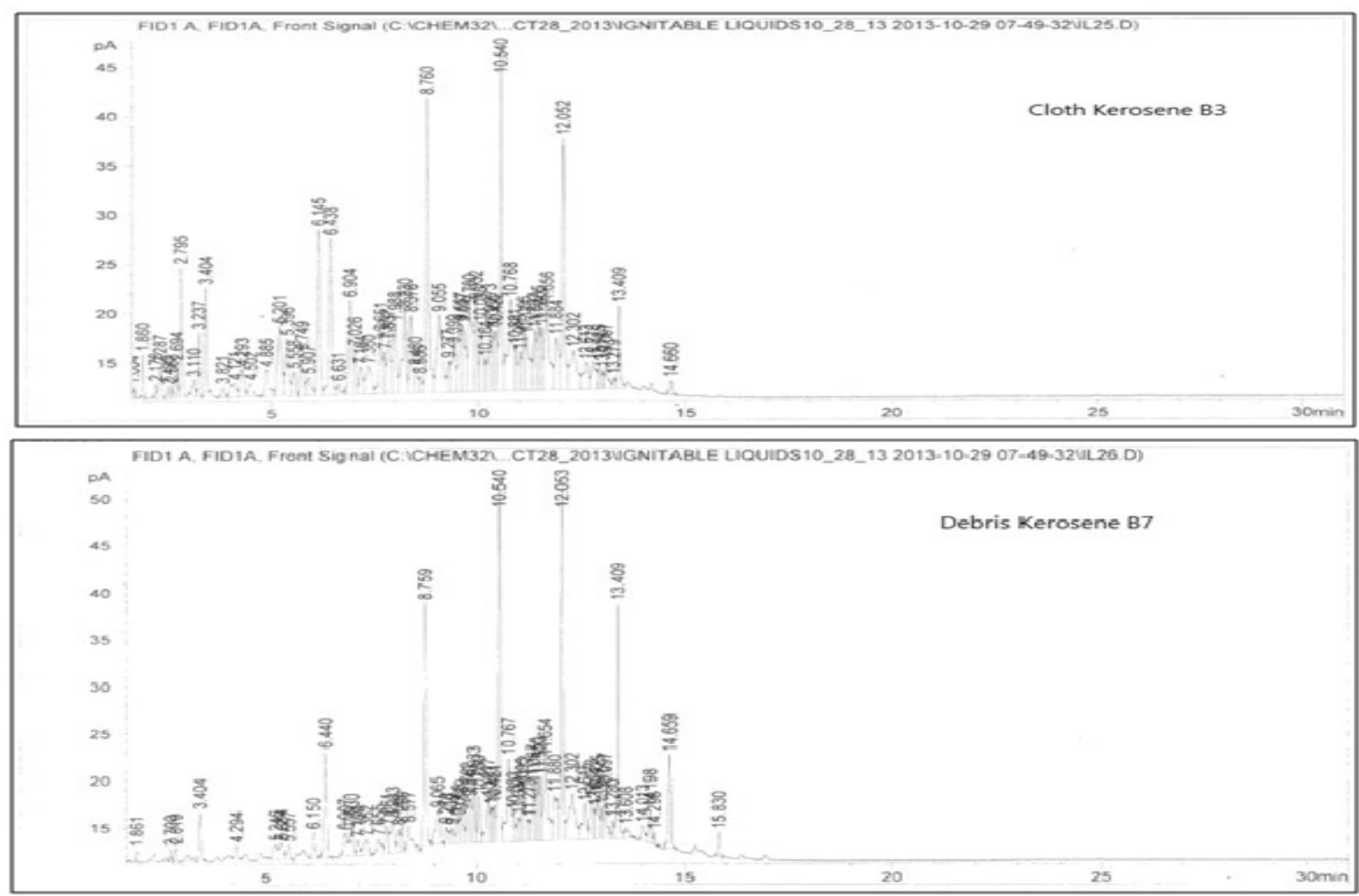

Figure 8a: Illustrating the chromatogram pattern for weathered burnt sand and soil and concrete diesel samples. 
Citation: Wright L, Reid I (2017) Classification of Weathered Kerosene and Diesel Fuel using Passive Headspace Concentration with Activated Charcoal Strip and Statistical Analysis Technique. J Forensic Res 8: 403. doi: 10.4172/2157-7145.1000403

Page 9 of 10

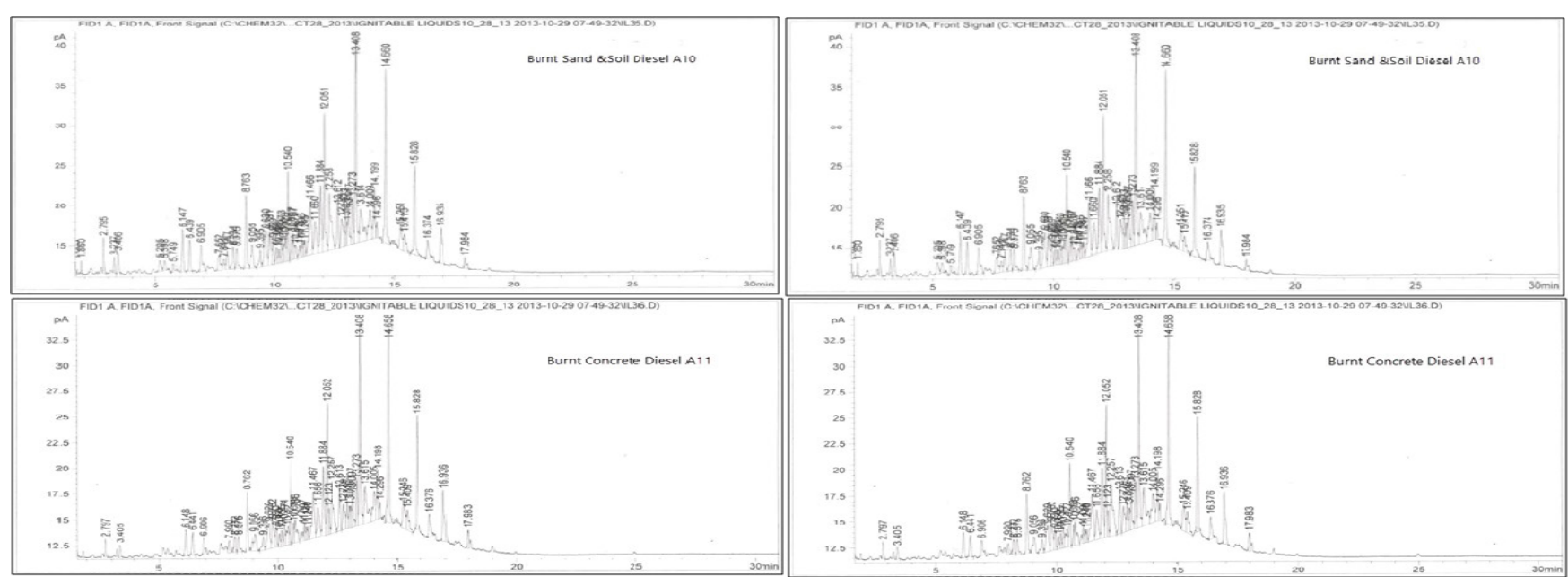

Figure 8b: Illustrating chromatogram pattern for weathered burnt concrete and sand and soil kerosene samples.

Error analysis was also performed on the data to determine the validity of the dataset. The two error analysis included supervised learning algorithm and supervised learning assessment. The supervised learning algorithm used the linear discrimination analysis, which was the most suitable algorithm since it produced the smallest error rate of $2.08 \%$. Hence, each time the model is asked to identify one of the unknown ignitable liquids $97.92 \%$ it will be correct. The second error analysis, learning assessment supervised, used the resampling method leave-one-out algorithm which is also a cross validation of the dataset. This final error estimate was significant as it showed that the samples in the dataset can both be discriminated and identified with high level of confidence. Hence producing an error rate of $20.83 \%$ indicating that each time the model is asked to identify an unknown ignitable liquid $79.17 \%$ of the time it will be correct.

The clusters of weathered kerosene and diesel fuel (case study 1 and 2) were formed based on similarities and differences in the characteristics of their n-alkanes while clusters of unweathered kerosene and diesel (case study 3) were based on the additional characteristics of the components of the materials in the sample. The weathered sand and soil of both kerosene and diesel of case study 4 showed similar clustering to that of case study 3 (Appendix A).

The data obtained from GC-FID was entered in to excel spreadsheet and then executed in Tanagra software. The dataset generated five clusters of kerosene and diesel using PCA. Kerosene Clusters B and D and Diesel Clusters A, C and E. The clusters were based on differences and similarities of the factors of both ignitable liquids as well as the type of materials used. Weathered kerosene cloth and burnt debris formed a close or tight clustering similar to that of weathered diesel cloth and burnt debris [11].

\section{Conclusion}

This research was done to show that the headspace technique alone cannot used to visually distinguish between weathered kerosene and diesel fuel even under various conditions of burning and weathering on the basis of $\mathrm{n}$-alkane data derived from GC-FID technique. This is based on the observation that the more weathered kerosene and diesel become the more difficult it is to visually distinguish them based on chromatogram pattern. Also, one of the analytical problems in differentiation is there are only small quantitative differences in their chemical composition [1].

Based on the Tanagra's PCA feature the similarities and differences of factors in variables are compared and grouped therefore the variables of the compounds in weathered and unweathered kerosene and diesel fuel are compared and grouped according their factors. Hence, the software will be able to use PCA to identify unknown ignitable liquids according to their grouped or cluster. Therefore GC-FID technique coupled with statistical technique will enable the analyst to more accurately distinguish between weathered kerosene and diesel fuel [1].

\section{Acknowledgement}

The authors would like to acknowledge the consultative input of $\mathrm{Dr}$ Tanya Kerr, Lecturer at the University of the West Indies, Mrs. Nadine Brown, Manager of Sustainable Development and Regional Planning of Planning Institute of Jamaica.

The authors would also like to express gratitude to Ms. Yeonie Campbell and Mr. Jovan Williams from the Biology and Administrative Department respectively, at the Institute of the Forensic Science and Legal Medicine, for providing the materials necessary for the research.

\section{References}

1. Zadora G (2005) Differentiation between weathered kerosene and diesel fue using automatic thermal desorption-GC-MS analysis and the likelihood ratio approach. J Sep Sci 28: 1467-1475.

2. Daeid NN (2004) Fire investigation. CRC Press 155-181.

3. Bawase MA, Reve SD, Shete SD Saraf MR (2012) Carbon number distribution by gas chromatography for identification of outlying diesel sample. AdMet.

4. Daeid NN (2007) Introduction and laboratory analysis. University Of Strathclyde Svare Professional Engineering (UK) LLP.

5. Stephanie DS, O'Carroll DM, Gerhard JI (2013) Wettability contrasts between fresh and weathered diesel fuels. J Contam Hydrol. 144 46-57.

6. Vladimir BP, Gordana GC, Branimir J, Miroslav MV (2012) Gas chromatography in environmental sciences and evaluation of bioremediation.

7. Designation: E 1412-00 (Reapproved 2005) Standard Practice for Separation of Ignitable Liquid Residues from Fire Debris Samples by Passive Headspace Concentration with Activated Charcoal

8. Gil O (2012) Age dating of middle-distillate fuels released to the subsurface environment.

9. Regenesis RegenOX Tech Bulletin 10.0. (1994) Total Petroleum Hydrocarbon Analysis: Analytical Challenges and Recommendations. 
Citation: Wright L, Reid I (2017) Classification of Weathered Kerosene and Diesel Fuel using Passive Headspace Concentration with Activated Charcoal Strip and Statistical Analysis Technique. J Forensic Res 8: 403. doi: 10.4172/2157-7145.1000403

Page 10 of 10

10. Daeid NN, Ismail D, Mat-Desa WNS, Savage K (2011) Application of unsupervised chemometric analysis and self-organizing feature map (SOFM) for the classification of lighter fuels. Anal Chem 82: 6395-400.
11. Mat-Desa WN, Ismail D, NicDaeid N (2011) Classification and source determination of medium petroleum distillates by chemometric and artificial neural networks: A self-Organizing feature approach. Anal Chem 8: 7745-54. 